\title{
Correspondance
}

\section{Dealing with incompetence}

The description in a recent 1 "Query" of the longest-serving physician in Dr. Ursus's hospital ${ }^{1}$ raises numerous questions. In particular, where were Dr. C's departmental head, the chief of staff, the hospital's quality assurance committee and its credentials committee, the senior administrator, the CEO? All of these parties have a duty to deal with incompetent health care professionals. That Dr. C did not attend morbidity and mortality rounds would in itself be a reason to revoke his privileges.

Other questions come to mind: Why do we call a physician with high ethical standards, like the one who "has been waging a battle with Dr. C for years," a "troublemaker"? Why don't we call him or her "Dr. Integrity"?

I have witnessed an almost identical situation, in which all of the players mentioned above were involved and did nothing. In that case, Dr. Integrity was a member of the hospital's board of directors, but when the problem reached that level, the other board members wrote to the minister of health requesting that Dr. Integrity be removed from his board position. The board's inaction in the face of knowledge of the problem rendered their liability insurance null and void, and each board member could have been found personally liable if a legal suit had been started.

Even the provincial college of physicians and surgeons was uncertain about how to deal with a complaint by Dr. Integrity concerning another physician's competence. In contrast, if the case had involved sexual misconduct, the college would have immediately started an investigation.

When we see medical incompetence today, we can no longer stick our heads in the sand, regardless of the status and reputation of the incompetent member of the health care team. Perhaps it is time to introduce the Swedish "lex Maria" to Canada. This law dictates that when a patient has been injured or has become sick while receiving medical care, or there is a risk that injury or illness could happen, even because of such things as insufficient competence, staffing, equipment or facilities, the department of health should be notified. ${ }^{2}$ Such a process might decrease the medical errors and patient deaths that we now hear so much about, ${ }^{3}$ at least the ones that are due to professional incompetence.

\section{Jan O. Sundin}

General Surgeon

South Shore Regional Hospital

Bridgewater, NS

\section{References}

1. CMA7 2004;170(8):1360

2. Ödegård S. From punishment to prevention? Medical errors reported in Sweden in 1989 and 1993. Saf Sci Monitor [serial online] 1999;3(article 1):1-10. Available: www.general.monash.edu.au /muarc/IPSO/vol3/te1.pdf (accessed 2004 Aug 3).

3. Baker GR, Norton PG, Flintoft V, Blais R, Brown A, Cox J, et al. The Canadian Adverse Events Study: the incidence of adverse events among hospital patients in Canada. CMA7 2004; 170(11):1678-86.

DOI:10.1503/cmaj.1040801

\section{Adverse events: past and future}

$\mathrm{T}$ he article by Alan Forster and associates ${ }^{1}$ on adverse events among patients admitted to a Canadian teaching hospital might suggest that this aspect of patient safety is of only recent interest and concern. However, CMA7 readers may be interested to learn of a study with similar findings that we published in CMAJ in 1967. 2,3 The methods used for the 2 studies differed, in that the earlier study used concurrent reporting and multiple means of detection (rather than a chart review) and was limited to a medical inpatient unit (rather than an entire hospital). We found that $24 \%$ of 731 patients had onset of an adverse event after admission to hospital, whereas the rate was $5 \%$ of 502 patients in the recent study. Reactions to drugs accounted for $62 \%$ of adverse events in the earlier study and $50 \%$ in the recent study, and nosoco- mial infections accounted for $9 \%$ and $19 \%$ of adverse events respectively. The latter difference may be explained by the inclusion of surgical patients in the recent study. Both studies concluded that most of the adverse drug events were preventable $(81 \%$ and $67 \%$ respectively).

Identifying adverse events is an important step in prevention. Our recognition of overdose with digoxin ${ }^{2,3}$ led to an educational approach that resulted in an important reduction in the incidence of those events. ${ }^{4}$

\section{John Ruedy \\ Professor (Emeritus) of Pharmacology \\ Dalhousie University \\ Halifax, NS \\ Richard I. Ogilvie \\ Professor (Emeritus) of Pharmacology and Medicine \\ University of Toronto \\ Toronto, Ont. \\ References \\ 1. Forster AJ, Asmis TR, Clark HD, Al Saied G, Code CC, Caughey SC, et al. Ottawa Hospital Patient Safety Study: incidence and timing of ad- verse events in patients admitted to a Canadian teaching hospital. CMA7 2004;170(8):1235-40. \\ 2. Ogilvie RI, Ruedy J. Adverse reactions during hospitalization. CMA7 1967;97(24):1445-50. \\ 3. Ogilvie RI, Ruedy J. Adverse drug reactions dur- ing hospitalization. CMA7 1967;97(24):1450-7. \\ 4. Ogilive RI, Ruedy J. An educational program in digitalis therapy. $7 A M A$ 1972;222:50-5.}

Competing interests: None declared.

DOI:10.1503/cmaj.1040765

$\mathrm{P}$ ublished evidence abounds on the role of hospital pharmacists in preventing adverse drug events and improving patient outcomes within hospitals. ${ }^{1-3}$ However, as the study by Alan Forster and colleagues ${ }^{4}$ demonstrates, many of the adverse medication-related events that patients experience occur outside the practice setting of hospital pharmacists.

The Canadian Society of Hospital Pharmacists promotes more seamless approaches to patient care and enhanced sharing of clinical information among hospital and community physicians and pharmacists. Use of a comprehensive electronic health record 
across multiple care jurisdictions can improve information flow and appropriate prescribing and monitoring of medications. Furthermore, many hospital pharmacists and physicians have implemented discharge prescription and communication tools (known variously as prescription/discharge notes form, discharge prescription form, pharmacy discharge letter and pharmacy discharge summary ${ }^{5-7}$ ) to enhance transfer of patient information to their primary care colleagues.

We hope that the evidence of the positive impact of hospital pharmacists $^{1-3}$ will prompt implementation of similar models of interdisciplinary care in the broader health care community to improve patient outcomes and enhance the safety of our system.

\section{Neil Johnson}

President

\section{Myrella T. Roy}

Executive Director

Canadian Society of Hospital Pharmacists

Ottawa, Ont.

\section{References}

1. Leape LL, Cullen DJ, Clapp MD, Burdick E, Demonaco HJ, Erickson JI, et al. Pharmacist participation on physician rounds and adverse drug events in the intensive care unit [published erratum appears in $7 A M A$ 2000;283(10):1293]. 7AMA 1999;282(3):267-70.

2. Bond CA, Raehl CL, Franke T. Clinical pharmacy services, hospital pharmacy staffing, and medication errors in United States hospitals. Pharmacotherapy 2002;22(2):134-47.

3. Kaushal R, Bates DW, Landrigan C, McKenna KJ, Clapp MD, Federico F, et al. Medication errors and adverse drug events in pediatric inpatients. FAMA 2001;285(16):2114-20.

4. Forster AJ, Asmis TR, Clark HD, Al Saied G, Code CC, Caughey SC, et al. Ottawa Hospital Patient Safety Study: incidence and timing of adverse events in patients admitted to a Canadian teaching hospital. CMA7 2004;170(8):1235-40.

5. Zwicker LA, MacKinnon NJ. Documentation requirements for seamless care. MacKinnon NJ, editor. In: Seamless care: a pharmacist's guide to continuous care programs. Ottawa: Canadian Pharmacists Association; 2003. p. 73-86.

6. Rogers K, Tierney M, Singh A, McLean W. Assessment of a seamless care prescription/discharge notes form. Can 7 Hosp Pharm 2003; 56:14-23.

7. Grad R, Mallet L. Improving communication between hospitals and community providers: the role of a pharmacy discharge letter. Can 7 Hosp Pharm 1998;51:23-5.

Competing interests: None declared.

DOI:10.1503/cmaj.1040721

\section{[Two of the authors respond:]}

$W^{\text {e were not previously aware of }}$ the work done by Richard Ogilvie and John Ruedy, ${ }^{1,2}$ and we are grateful to them for bringing this research to our attention. We acknowledge that systematically tracking complications is not a new idea; it dates back at least as far as Ernest Codman's "end results" concept in the early 1900 s. ${ }^{3,4}$

Ogilvie and Ruedy's earlier study has
2 important implications. The first relates to the difference in risk of in-hospital "adverse reactions" between their study and ours: this risk was $24 \%$ among medical patients in 1965/66 but only $6 \%$ in our study and approximately $7 \%$ in the Canadian Adverse Events Study. ${ }^{6}$ Although this discrepancy could be due to differences in study methods, it might also relate to improvements in health care safety in Canada. This observation challenges the popular notion that health care is in a "crisis."

The second point relates to the method of detecting adverse reactions. The earlier study was based on voluntary reporting by physicians and nurses. Experience at our institution and elsewhere ${ }^{8}$ has shown that incident reporting tools usually capture minor, clinically insignificant events while missing serious outcomes. Therefore, it would be interesting to study and implement the strategies that Ogilvie and Ruedy used in their study to encourage health care workers to report adverse events.

Neil Johnson and Myrella Roy point out the need for integrated pharmacy information systems. We agree that this is an important step toward improving the safety of outpatient prescribing. As recently noted by Tamblyn and colleagues, ${ }^{9}$ patients often have prescrip- 